\title{
CATALYST POISONING AND FIXED BED REACTOR DYNAMICS
}

\author{
H. S. WENG $\dagger$, G. EIGENBERGER $\ddagger$ and J. B. BUTT§ \\ Department of Chemical Engineering and Ipatieff Catalytic Laboratory, Northwestern University,
} Evanston, IL 60201, U.S.A.

(Received 25 January 1975; accepted 16 April 1975)

\begin{abstract}
The poisoning kinetics of thiophene on Ni-kieselguhr catalysts and the deactivation behavior of nonisothermal fixed bed reactors have been studied experimentally using benzene hydrogenation as a model exothermic reaction. The time dependent axial temperature profiles in the reactors were measured and compared with values evaluated from a dispersion model, the parameters of which have been determined in separate experimentation.

Poisoning kinetics were measured in a series of differential reactor experiments at atmospheric total pressure, thiophene partial pressures of $0 \cdot 037-0 \cdot 19$ torr, hydrogen to benzene molar ratios $>8 / 1$ and temperatures from $60-180^{\circ} \mathrm{C}$. Excellent agreement was found with a power law equation for the rate of change of activity with time, first order in catalyst activity and in thiophene concentration, with an experimental activation energy of $1080 \mathrm{kcal} / \mathrm{kmole}$.

This correlation of poisoning kinetics, however, was not able to predict the propagation of the zone of activity (hot-spot) on poisoning of an integral fixed bed reactor. Initial (steady state) temperature profiles were modeled satisfactorally, but the rate of migration of the hot spot was found experimentally to be more rapid than that predicted from the correlation of poisoning kinetics. A semi-empirical two site deactivation model is shown to resolve the discrepancy.
\end{abstract}

\section{INTRODUCTION}

The problem of catalyst deactivation in fixed bed reactors is widely encountered in processing applications, yet relatively few studies, particularly those giving experimental results, have been reported in the literature. The bulk of results both theoretical and experimental, have been summarized in a recent review by Butt[1]. Eberly $e t$ al.[2] conducted a study of coke formation for cumene cracking in a fixed bed of silica-alumina catalyst. They found that coke formation was a complex function of the length of the cracking cycle and space velocity. Menon and Sreeramamurthy[3] and Menon et al.[4] have measured the time dependence of temperature profile and reaction rate in a fixed bed of charcoal catalyst used for the air oxidation of $\mathrm{H}_{2} \mathrm{~S}$. No quantitative interpretation of these results have been presented. Kunigita et al. [5] have reported the results of a systematic investigation of coke formation in fixed bed reactors. The experimental system was dehydrogenation of n-butane over alumina-chromia catalysts; they analyzed coke formation effects on the overall efficiency of fixed bed processing using an analog computer technique.

Recent experimental studies are represented by the work of Lambrecht et al.[6] who investigated the coking of a platinum reforming catalyst in the isomerization of n-pentane. They evaluated the parameters appearing in the deactivation model of Froment and Bischoff [7] by fitting experimental conversion-time variation and coke profiles with both differential and integral methods. Pexidr et al. [8] measured the axial concentration and tempera-

†Current address: Department of Chemical Engineering, Cheng Kung University, Tainan, Tawain, Republic of China.

$\ddagger$ Current address: Institut für Systemdynamik und Regelungstechnik, Universität Stuttgart, Stuttgart, Germany.

$\S$ To whom correspondence should be addressed. ture profiles in a non-isothermal, non-adiabatic pilot plant reactor during the deactivation of a $\mathrm{Ni}$ catalyst by $\mathrm{CS}_{2}$ in benzene hydrogenation, which is the reaction used here. However, they did not attempt to model the transient behavior of the reactor under deactivation conditions.

Richardson [9] obtained the activity profiles of an isothermal fixed bed reactor on sulfiding of a $\mathrm{Ni}$ kieselguhr catalyst through the measurement of the relative ferromagnetic properties of sulfided and unsulfided portions of the bed. It was confirmed that sulfiding (with thiophene and a number of other sulfur compounds) kinetics could be explained by the Bohart-Adams[10] theory of wave propagation through fixed beds. As will be seen in the results of this study, such a theory does not appear adequate for non-isothermal reaction systems.

\section{RESEARCH PROBLEM}

The main objectives of this research are to obtain further experimental information on the poisoning of fixed bed reactors and to explore the adequacy of simple models to explain the behavior of the reactor in both steady and transient states. The effect of operating parameters on reactor performance are reported for the benzene hydrogenation reaction over Ni-kieselguhr catalyst with thiophene as the catalyst poison.

\section{EXPERIMENTAL}

\section{Reactor and flow system}

The experimental flow system is shown in Fig. 1. It is similar to that described by Irving and Butt[11] except that the reactor section is a tubular fixed bed and there are two separate inlet systems to permit switching from thiophene-free to thiophene-containing feed. Three major series of experiments were carried out. In the first a small differential reactor was employed to measure kinetics of the benzene hydrogenation and of the poisoning reaction 


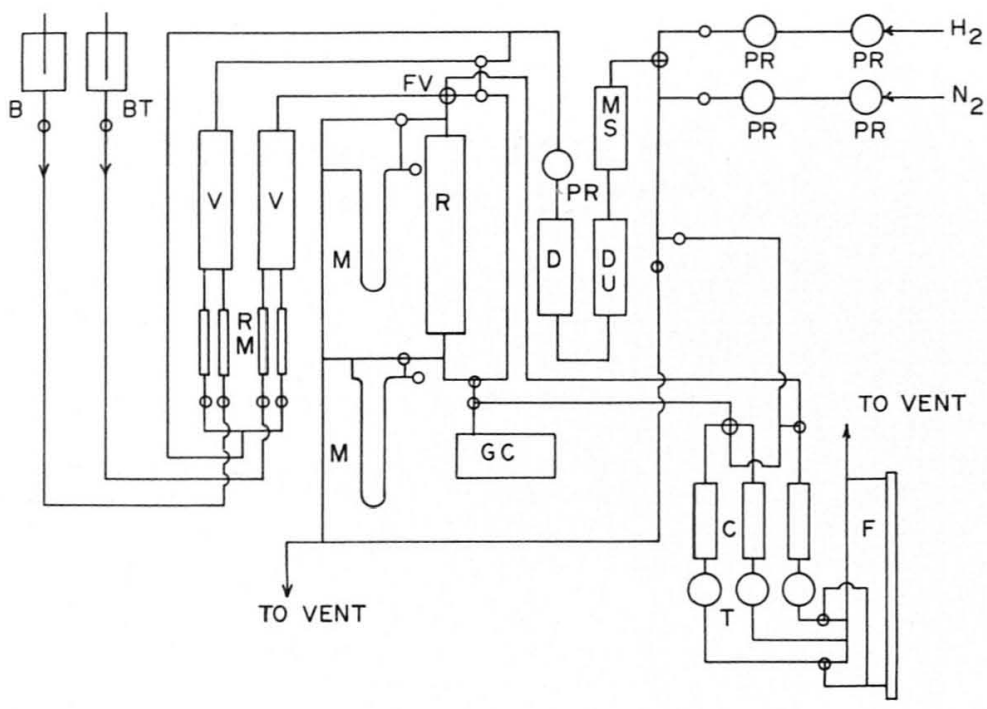

Fig. 1. Schematic of Flow Reactor System. B, Benzene storage; BT, Benzene/thiophene storage; C, Condenser; D, Drier; DU, Deoxo unit; F, Flowmeter; FV, Four-way valve; M, Manometer; MS, Molecular sieve; PR, Pressure regulator; R, Reactor; RM, Rotameter; T, Trap; V, Vaporizer; GC, Gas Chromatograph.

under the experimental conditions of interest; in the second the absorption capacity of the catalyst for thiophene under reaction conditions was determined, also with a tubular fixed bed arrangement. The third series of experiments, to measure reactor transients under poisoning conditions, employed a concentric, double-tubing glass reactor. The inner tube was wound with Nichrome resistance wire and the outer tubing with heating tape. These were used to heat the reactor for catalyst pre-treatment and to initiate reaction at the start of a run. The inner tube was packed in three layers, fore and aft sections of inert glass beads of the same mesh size as the catalyst, and a central section of catalyst diluted $2: 1$ with glass beads. A $3 \mathrm{~mm} \mathrm{O.D.} \mathrm{thermocouple} \mathrm{guide} \mathrm{containing}$ a movable iron-constantan thermocouple passed along the entire axis of the reactor. Reactor dimensions and conditions of the deactivation transient experiments are given in Table 1 .

\section{Materials}

Prepurified grade hydrogen and nitrogen, and high purity grade helium, supplied by Linde, were used in all experiments. All gases were passed through a purification train of $13 \mathrm{X}$ sieve traps for removal of moisture and, in the case of $\mathrm{H}_{2}$, an Englehard Deoxo unit upstream of a second drier. A.C.S. certified thiophene-free reagent grade benzene, supplied by Fisher Scientific Company, and reagent grade thiophene, supplied by Eastman Organic Chemicals, were used for the liquid feeds. The catalyst was Harshaw Ni-0104T, 58\% nickel by weight, crushed to 20/40 or 12/20 U.S. standard mesh for the differential and integral reactor experiments, respectively. Harshaw reports the active nickel surface in the reduced catalyst to be approximately $24 \mathrm{~m}^{2} / \mathrm{g}$. Pyrex glass particles of $12 / 20 \mathrm{mesh}$ were used to fill the fore and aft reactor sections and for catalyst dilution.

\section{Operation}

Catalyst pretreatment consisted of purging the reactor system at room temperature with nitrogen at $1000 \mathrm{~cm}^{3} / \mathrm{min}$ for $1 \mathrm{hr}$, then increasing temperature to $120^{\circ} \mathrm{C}$ and reducing flow to $200 \mathrm{~cm}^{3} / \mathrm{mm}$ for $3 \mathrm{hr}$. The temperature was then increased to $160^{\circ} \mathrm{C}$ and hydrogen introduced into the system for $10 \mathrm{hr}$. This pretreatment was repeated before each series of runs. In the experiments to measure transients of the integral reactor

Table 1. Experimental conditions for fixed bed poisoning runs

\begin{tabular}{|c|c|c|c|c|c|c|c|}
\hline Operating Condition & Run: & G1 & $\mathrm{G} 2$ & G3 & $\mathrm{G}_{4}$ & G5 & c7 \\
\hline Total pressure (inlet), & torr & 750.1 & 741.7 & 749.0 & 741.7 & 742.7 & 749.0 \\
\hline Total flow rate, $\mathrm{ml} / \mathrm{min}$ & $(\mathrm{sc})$ & 1034.2 & 1049.6 & 1551.5 & 1049.6 & 1050.4 & 1554.0 \\
\hline Ambient temp., ${ }^{\circ} \mathrm{C}$ & & 19.0 & 23.0 & 22.0 & 23.0 & 23.0 & 22.0 \\
\hline Inlet temp., ${ }^{\circ} \mathrm{C}$ & & 45.5 & 55.0 & 54.4 & 45.2 & 45.5 & 55.0 \\
\hline Mole fraction $\mathrm{C}_{6} \mathrm{H}_{6}$ & & 0.028 & 0.043 & 0.033 & 0.043 & 0.043 & 0.035 \\
\hline Mole fraction $\mathrm{H}_{2}$ & & 0.972 & 0.957 & 0.967 & 0.957 & 0.957 & 0.965 \\
\hline Thiophene/ $\mathrm{C}_{6} \mathrm{H}_{6} \times 10^{2}$ & & 1.136 & 1.136 & 1.136 & 1.136 & 0.565 & 0.565 \\
\hline
\end{tabular}

All experimental runs with: reactor radius $=0.822 \mathrm{~cm}$; reactor length $=50.00 \mathrm{~cm}$; entrance section length $=$ $14.00 \mathrm{~cm}$; catalyst section length $=9.50 \mathrm{~cm}$; Catalyst wt. $=6.876 \mathrm{gm}$. Catalyst bulk density $=0.354 \mathrm{~g} / \mathrm{cm}^{3} ; 2: 1$ (volume) dilution with 12/20 mesh glass beads: 12/20 mesh Ni-0104T. 
due to deactivation separate hydrogen flows were introduced into two vaporizers, after catalyst activation, as shown in Fig. 1. One vaporizer was fed with pure benzene while the second was fed a benzene-thiophene mixture of fixed concentration. Initially the pure benzene was fed to the reactor while the thiophene containing feed was directed through an inert bed (not shown in Fig. 1) of the same pressure drop as the reactor. The flow rates of hydrogen and liquid to vaporizer in both feed systems were adjusted to the same values and allowed to stabilize. After the reactor had attained steady state, as indicated by invariance of the temperature profile measured along the axis of the reactor, and inlet and exit concentrations had been measured, the feed was switched to introduce the thiophene-containing mixture into the reactor and the pure benzene feed to the secondary bed. The reactor temperature profile and inlet and exit concentrations were then measured at periodic time intervals.

\section{Analytical}

Gas chromatography was used to analyze reactants and products at both the inlet and outlet of the reactor. An F \& M 700 laboratory chromatograph with a $12 \mathrm{ft}$ section of $\frac{11}{4}$ stainless steel column packed with $15 \%$ Carbowax (6000) on $80 / 100$ mesh chromosorb $P$ was used for benzene/cyclohexane analysis. Operating conditions were those as described by Kehoe[12]. Thiophene concentrations were determined with a Coleman Model 14 Spectrophotometer, using the JIS isatin-sulfuric acid method [13].

\section{Reaction kinetics}

The benzene hydrogenation reaction on nickel-kieselguhr has been investigated at the conditions of the present experiment by Kehoe and Butt[14], who correlated the kinetics by the form:

$$
-r_{B}=\frac{k_{i}^{0} K^{0} \exp [(-Q-E) / R T] P^{2} x_{B} x_{H}}{1+K^{0} \exp (-Q / R T) P x_{B}}
$$

The values of $k_{i}^{0}, K^{0}, E$ and $Q$ were redetermined in separate experiments for the batch of catalyst used in this study [13] using a differential reactor under the same conditions given in Table 1. Rate parameters were determined in two series of experiments corresponding to limiting forms of eqn (1). The first was at low temperature and high benzene concentration where:

$$
-r_{B} \approx P x_{H} k_{i}^{0} \mathrm{e}^{-E / R T}=P x_{H} \cdot k_{1}(T)
$$

and the second at high temperature and low benzene concentration, where:

$$
-r_{B} \approx P^{2} x_{B} x_{H} \mathrm{e}^{(-Q-E) / R T}=P x_{B} x_{H} \cdot k_{2}(T) .
$$

These experimental data are shown in Fig. 2 and the results obtained by nonlinear least squares fit are summarized in Table 2.

\section{Poisoning kinetics}

Kinetics of the poisoning reaction were also determined
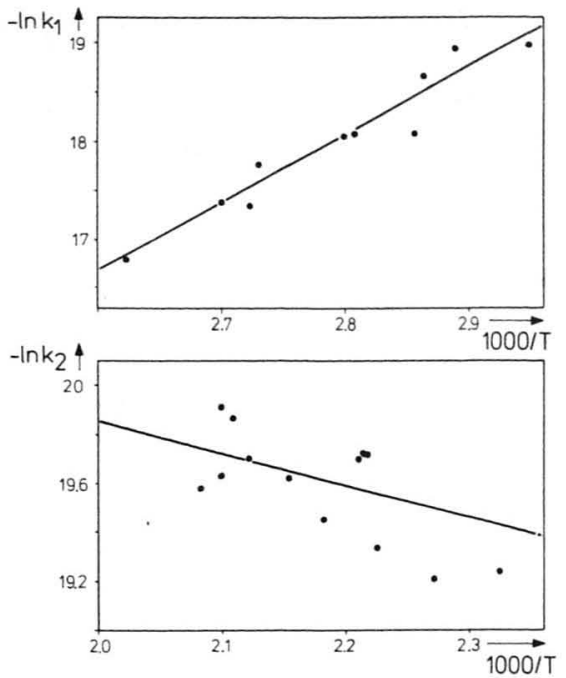

Fig. 2. Correlation of experimental data for benzene hydrogenation, eqn (1). $k^{0}=k_{i}^{0} \mathrm{e}^{-E / R T} ; K=K^{0} \mathrm{e}^{-Q / R T}$. Upper: $T$ low, $x_{B}$ high; $r_{B} \approx P x_{H} \cdot k_{1}(T)$; Lower: $T$ high, $x_{B}$ low; $r_{B} \approx$ $P^{2} x_{B} x_{H} \cdot k_{2}(T)$.

Table 2. Parameters for benzene hydrogenation kinetics

$$
\begin{aligned}
& \mathrm{E}=13,770 \mathrm{kcal} / \mathrm{kmole} \\
& \mathrm{k}_{1}^{0}=4.22 \mathrm{kmole} / \mathrm{kg}-\mathrm{sec}-\text { torr } \\
& Q=-16,470 \mathrm{kcal} / \mathrm{kmole}^{\mathrm{e}} \\
& \mathrm{K}^{0}=4.22 \times 10^{-11} \text { torr }^{-1}
\end{aligned}
$$

in separate experimentation. The analysis of deactivation rates was carried out based on a separable [15] form of rate equation, linear in concentration of poison and availability of active sites. Thus:

and

$$
-r_{d}=k_{d}^{0} \mathrm{e}^{-E_{D} / R T} P x_{T} \theta_{A}
$$

$$
k^{0}=k_{i}^{0} \theta_{A}
$$

where $\theta_{A}$ is the ratio of the number of active sites to that under initial conditions and $k^{0}$ is the rate constant to be used in place of $k_{i}^{0}$ in eqn (1) as the catalyst deactivates. A similar rate equation for poisoning has been used by Richardson [9] for sulfur poisoning of Ni-kieselguhr, and good agreement with eqn (2) was obtained in the present study for temperatures from 65 to $175^{\circ} \mathrm{C}$ and thiophene partial pressures from 0.037 to 0.19 torr. Experimental results are shown in Fig. 3 and the values determined for $k_{d}{ }^{0}$ and $E_{d}$ are given in Table 3. However, while our experimental results in this range were correlated by eqn (2), there is evidence from the fixed bed studies which we discuss subsequently that poisoning kinetics may be rather more complicated than this.

\section{Fixed bed deactivation}

A number of typical initial (steady state) temperature profiles are shown in Fig. 4. These demonstrate the

Table 3. Parameters for thiophene poisoning kinetcs

$$
\begin{aligned}
& E_{d}=1080 \mathrm{kcal} / \mathrm{kmole} \\
& k_{d}^{0}=2.40 \times 10^{-2}(\text { torr }-\mathrm{sec})^{-1}
\end{aligned}
$$



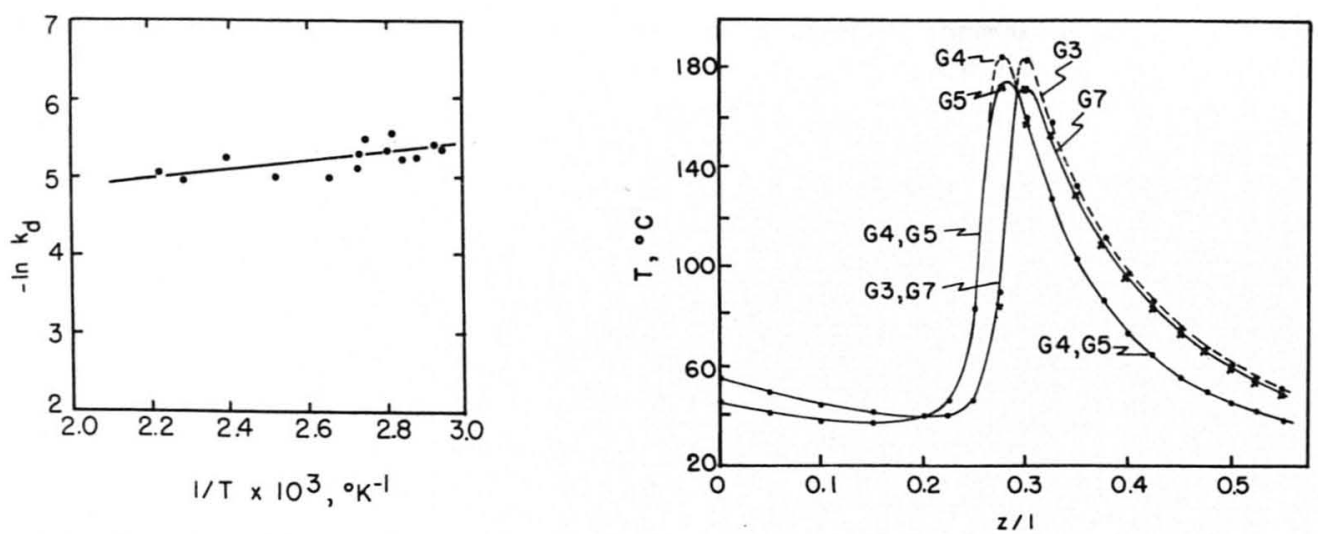

Fig. 3. Correlation of experimental data for thiophene poisoning, Fig. 4. Reproducibility of experimental temperature and convereqn (2). sion measurements.
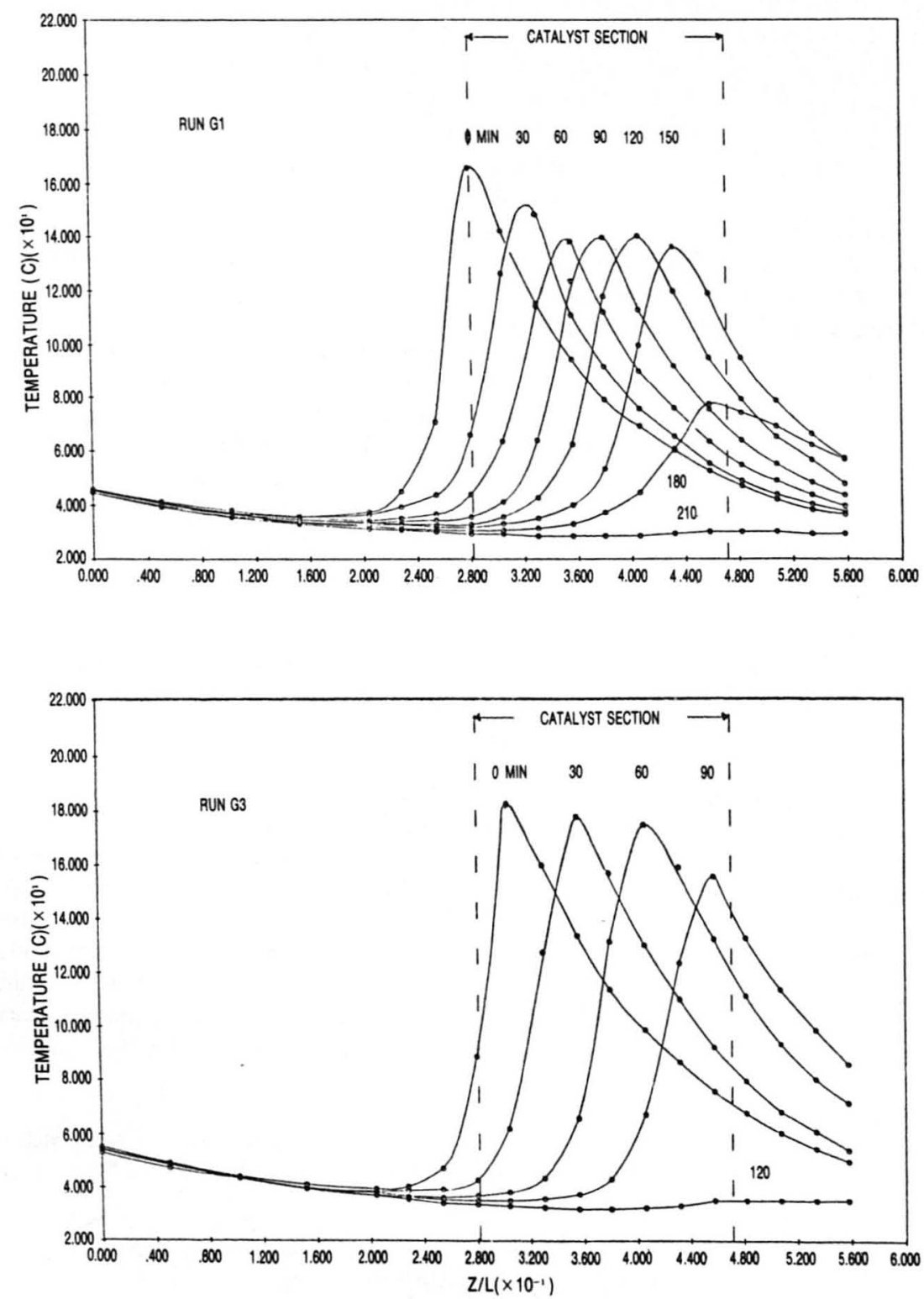

(a) 

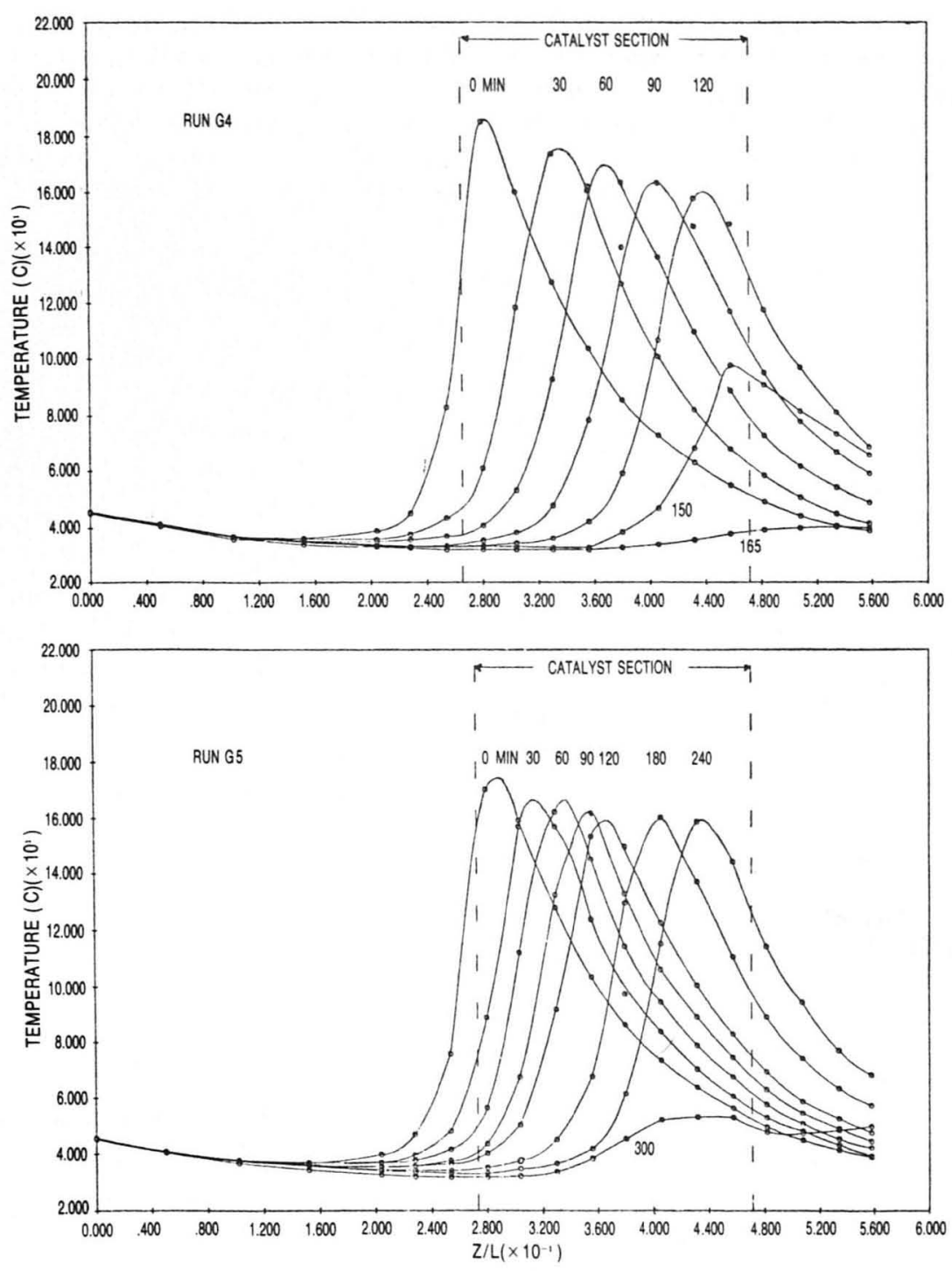

(b)

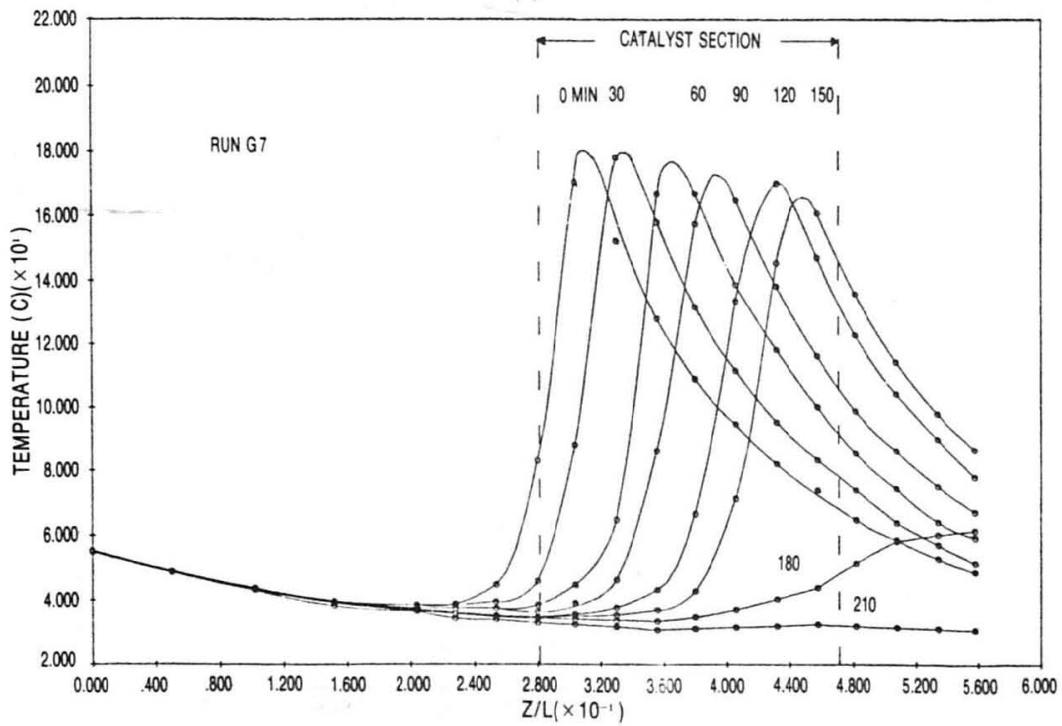

(c)

Fig. 5. Experimental temperature profile transients, Runs G1-G7. 
reproducibility of results for experiments at similar conditions. There are possible thermal conduction effects on the thermocouple measurements, however, since the temperature gradients along the axis are large. In a number of experiments the temperature at a given point was measured from opposite directions (i.e. both from the top and the bottom of the reactor); the maximum difference observed in any experiment was $5^{\circ} \mathrm{C}$. Radial gradients were also smaller than this in all cases. As will be seen, errors of this magnitude do not appear important in the interpretation of poisoning dynamics.

The time dependent temperature profiles measured for the runs listed in Table 1, except G2 $\dagger$, are shown in Fig. 5, and corresponding exit conversions in Fig. 6. A two-fold range of inlet benzene and thiophene concentration and a 1.5 fold variation in space velocity is encompassed by these experiments.

The temperature profiles in all cases move down the bed at almost constant speed, becoming a little broader as the end of the bed is approached. On reaching the end of the bed the hot spot diminishes in magnitude and then disappears within a short time interval. In runs $\mathrm{G} 3$ and $\mathrm{G} 4$ the movement of the profiles is more rapid due to higher thiophene feed content, while the profiles of G5 are wider and the hot spots a bit larger in magnitude, the result of lower flow rate through the bed. From the conversions shown in Fig. 6 it is seen that, from initial operation until near the end of a run, there is $100 \%$ conversion in each case, with a rapid fall-off near the end of operation. On comparison with the corresponding temperature profiles, it is seen that there is an excellent correlation between the rapid decrease in conversion and the movement of the hot spot out of the reactor.

\section{INTERPRETATION}

\section{Modeling the experimental system}

In view of the small reactor diameter involved in all experiments, a one dimensional axial dispersion model

$\lceil$ Although the experimental conditions for G2 differed from those for G3 almost exactly the same results were obtained. was used to model the reactor dynamics. As has been shown by Froment [16] and Finlayson [17] such a model is capable of accounting for the influence of a parabolic radial temperature profile if the wall heat transfer coefficient is chosen properly. The model includes material balance equations for benzene and thiophene, an energy balance, and the rate equation for catalyst deactivation. Since hydrogen was present in great excess the hydrogen concentration was essentially constant and volume contraction is not important. Thus we have:

(1) Mass balance, benzene

$$
\epsilon \frac{\partial C_{B}}{\partial t}=\epsilon D_{B} \frac{\partial^{2} C_{B}}{\partial z^{2}}-\epsilon \frac{\partial v C_{B}}{\partial z}+\theta_{A} \rho_{C} r_{B}\left(C_{B}, T\right) .
$$

(2) Mass balance, thiophene

$$
\epsilon \frac{\partial C_{T}}{\partial t}=\epsilon D_{T} \frac{\partial^{2} C_{T}}{\partial z^{2}}-\epsilon \frac{\partial v C_{T}}{\partial z}+\rho_{C} r_{T}\left(C_{T}, T, \theta_{A}\right) .
$$

(3) Energy balance

$$
\begin{gathered}
\frac{\partial T}{\partial t}=\frac{\lambda_{\text {eff }}}{\overline{\rho C_{p}}} \frac{\partial^{2} T}{\partial z^{2}}-\epsilon v \frac{\rho_{g} C_{p g}}{\overline{\rho C_{p}}} \frac{\partial T}{\partial z}+\frac{2 \alpha}{R_{r} \overline{\rho C_{p}}}\left(T_{w}-T\right) \\
+\frac{\theta_{A}\left(-\Delta H_{R}\right)}{\overline{\rho C_{p}}} \rho_{C} r_{B}\left(C_{B}, T\right) .
\end{gathered}
$$

(4) Activity decay

$$
\frac{\mathrm{d} \theta_{A}}{\mathrm{~d} t}=r_{d}\left(C_{T}, T, \theta_{A}\right)
$$

or

$$
r_{T}=M_{T} r_{d}
$$

The boundary conditions corresponding are, at entrance:

$$
\left.\frac{\mathrm{d} Y_{i}}{\mathrm{~d} z}\right|_{z=0}=\frac{v}{D_{i}}\left(Y_{i(z=0)}-Y_{i_{0}}\right)
$$

where $Y_{i_{0}}=$ feed values of $C_{B}, C_{T}$ and $T$, and at exit:

$$
\left.\frac{\mathrm{d} Y_{i}}{\mathrm{~d} z}\right|_{z=1}=0
$$

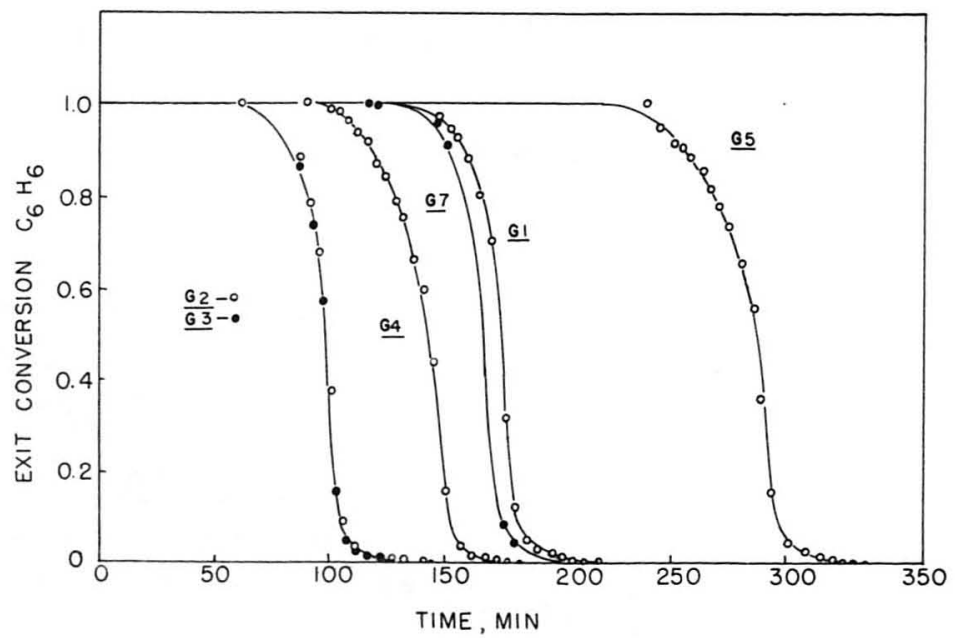

Fig. 6. Exit benzene conversion, all Runs. 
The experimental configuration consisted of a packed catalyst section between fore and aft sections of inert glass beads, so that in solution of these equations the reaction rate terms and eqn (7) are not employed for the inert sections. Equations (4)-(6) make no mention of intraparticle or intraphase gradients, and in fact experimental conditions and reactor configuration were chosen in accordance with the criteria summarized by Mears and by Butt and Weekman [18] to ensure the absence of such gradients. Interphase temperature gradients are the most difficult to avoid in this system. Under the most extreme conditions in these experiments (i.e. at the location of the hot spot) the criterion developed by Mears for a less than $5 \%$ deviation in rate due to interphase temperature gradients requires a Nusselt number $\left(h D_{p} / \lambda_{g}\right)$ of order 10 . Our experimental values, according to the correlation of Littman et al. [19], are of order 5. Given the scatter in that correlation, we feel our conditions to be in order of magnitude agreement with the criterion of Mears, and the use of a pseudohomogeneous model justified.

\section{Parameters}

There are a number of parameters which appear in the model equations in addition to the kinetics. These have either been evaluated in separate experiments or, when reliable data or correlation exists, determined from the literature. Parameters are taken to be constant over the length of the reactor and with time of operation. The values employed are given in Table 4. Two of the parameters appearing in Table $4, M_{T}$ and $\alpha$ are particularly important in the modeling results and we shall give some detail on their determination here.

The thiophene capacity of the catalyst, $M_{T}$, is required to compute the thiophene mass balance, accounting for irreversible adsorption on the catalyst surface. This was measured by monitoring exit thiophene concentration from a fixed bed under reaction conditions from start up with fresh catalyst until complete deactivation was observed (no cyclohexane in product). Benzene and hydrogen at 0.835 and $585 \mathrm{~cm}^{3} / \min (\mathrm{sc})$ were fed to a $2.5 \mathrm{~cm}$ dia. reactor containing $20.00 \mathrm{~g}$ of the reduced catalyst. Thiophene at a concentration of $5 \cdot 27 \times$ $10^{-3} \mathrm{~g} / \mathrm{cm}^{3}$ in the benzene was introduced and exit thiophene concentration monitored with the result shown in Fig. 7. Complete deactivation was observed at $11.0 \mathrm{hr}$, with corresponding full break through of thiophene to its inlet concentration. Reaction zone temperature during this experiment was about $180^{\circ} \mathrm{C}$. The amount adsorbed is determined as the difference in area between the two curves. On a relative basis $A_{1} /\left(A_{1}+A_{2}\right)$ is determined to be 0.597 , thus:

$$
\begin{aligned}
M_{T} & =(0.597)(0.835)\left(5.27 \times 10^{-3}\right)(660) / 20 \\
& =1.03 \times 10^{-3} \mathrm{kmole} / \mathrm{kg} \text { catalyst. }
\end{aligned}
$$

This corresponds to a value of $6.2 \times 10^{20}$ molecules $/ \mathrm{g}$ catalyst. Based on an active Ni surface of approx. $24 \mathrm{~m}^{2} / \mathrm{g}$ and unit stoichiometry for thiophene chemisorption per $\mathrm{Ni}$ atom, the number of adsorption sites is about $3 \times 10^{15} \mathrm{~cm}^{-2}$, a reasonable figure. For "five point" adsorption stoichiometry [22] the number is about $10^{16} \mathrm{~cm}^{-2}$. It is important to note that this capacity was measured under reaction conditions, since Lyubarskii et al.[22] have shown significantly higher thiophene uptakes on $\mathrm{Ni}$ at temperatures above $100^{\circ} \mathrm{C}$ as compared to room temperature or slightly higher.

The second parameter, $\alpha$, the wall heat transfer coefficient, was also determined experimentally, since there is a fair degree of uncertainty involved in using existing correlations, particularly for laboratory scale reactors. This was done using the measured temperature

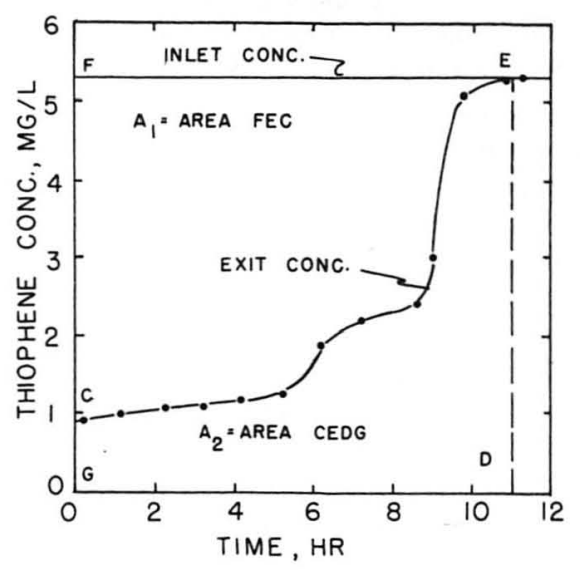

Fig. 7. Thiophene chemisorption under reaction conditions.

\begin{tabular}{|c|c|c|}
\hline Quantity & Evaluated from & Reference \\
\hline Mo1. wt. & $M W=2.106 x_{H}+78.12 x_{B}$ & - \\
\hline$P_{g}\left(\mathrm{~kg} / \mathrm{m}^{3}\right)$ & $f_{g}=(M W)(273.16) P /(22.41)(760) \mathrm{T}_{0}$ & - \\
\hline $\mathrm{C}_{\mathrm{pg}}\left(350^{\circ} \mathrm{K}\right)\left(\frac{\mathrm{kcal}}{\mathrm{kmo} 1 \mathrm{e}-{ }^{-} \mathrm{K}}\right)$ & $C_{P B}=6.935 x_{H}+23.15 x_{B}$ & API Tables \\
\hline$\lambda_{\text {eff }}\left(\mathrm{kcal} / \mathrm{m}-\mathrm{sec}-{ }^{\circ} \mathrm{K}\right)$ & $\lambda_{\text {eff }}=7 \lambda_{g}+0.8 \rho_{g} C$ pg ${ }^{v \in D}$ & \\
\hline & $\left(\lambda_{g} \approx \lambda_{\mathrm{H}_{2}}\right)$ & Yagi and Kuni [20] \\
\hline$D_{T}, D_{B}\left(m^{2} / s e c\right)$ & $D_{T}=D_{B}=D_{C_{6} H_{6} / H_{2}}=0.4 \times 10^{-4}\left(45^{\circ} \mathrm{C}\right)$ & $\begin{array}{l}\text { Krischer and Kröl1 } \\
{[21]}\end{array}$ \\
\hline$\alpha\left(\mathrm{kca} 1 / \mathrm{m}^{2}-{ }^{\circ} \mathrm{K}\right)$ & $\alpha=2.6 \times 10^{-3}$ & see text \\
\hline$\varepsilon$ & $\varepsilon=0.6$ & Weng [13] \\
\hline$\overline{\mathrm{PC}}\left(\mathrm{kcal} / \mathrm{m}^{3}-{ }^{\circ} \mathrm{K}\right)$ & $\overline{P C_{p}} \approx \bar{p} \cdot \overline{C_{p}}=175$ & - \\
\hline$M_{I}(\mathrm{kmole} / \mathrm{kg})$ & $M_{\mathrm{T}}=1.03 \times 10^{-3}$ & see text \\
\hline
\end{tabular}

Table 4. Parametric quantities for modeling fixed bed deactivation of Ni hydrogenation catalyst by thiophene 
profiles in the inert fore and aft reactor sections determined at initial (steady state) conditions in the poisoning experiments. The analytical solution of the energy balance without reaction and at steady state

$$
\lambda_{\text {eff }} \frac{\mathrm{d}^{2} T}{\mathrm{~d} z^{2}}-v \rho_{g} C_{p g} \frac{\mathrm{d} T}{\mathrm{~d} z}-\frac{2 \alpha}{R_{r}}\left(T-T_{w}\right)=0
$$

with B.C.: $T_{z=0}=T_{0}, T_{z=1}=T_{L}$ is:

$$
\begin{aligned}
T(z)= & T_{L}\left[\frac{\exp p_{2} z-\exp p_{1} z}{\exp p_{2} L-\exp p_{1} L}\right] \\
& +T_{0}\left[\frac{\exp \left(p_{2} L+p_{1} z\right)-\exp \left(p_{1} L+p_{2} z\right)}{\exp p_{2} L-\exp p_{1} L}\right] \\
+\frac{\alpha_{w}}{\alpha_{1}} & {\left[1+\frac{\left(\exp p_{1} L-1\right) \exp p_{2} z-\left(\exp p_{2} L-1\right) \exp p_{1} z}{\exp p_{2} L-\exp p_{1} L}\right] }
\end{aligned}
$$

where:

$$
\begin{aligned}
p_{1,2} & =\frac{\bar{v}}{2 \lambda_{\text {eff }}} \pm\left[\frac{\bar{v}^{2}}{2 \lambda_{\text {eff }}^{2}}+\frac{\alpha_{1}}{\lambda_{\text {eff }}}\right]^{1 / 2} \\
\alpha_{1} & =\frac{2 \alpha}{R_{r}} ; \quad \alpha_{w}=\frac{2 \alpha}{R_{r}} T_{w} \\
\bar{v} & =v \rho_{g} C_{p g} .
\end{aligned}
$$

A nonlinear least squares analysis was used to fit the measured temperature profiles in the inert front and back sections. Since wall temperatures could not be reliably measured, values for $T_{w}$ as well as $\lambda_{\text {eff }}$ and $\alpha$ were estimated by this method. It was found that $\lambda_{\text {eff }}$ was in good agreement with the correlation of Yagi and Kunii[19], so it was possible to fix $\lambda_{\text {eff }}$ and estimate only $\alpha$ and $T_{w}$.

The most probable value for $\alpha\left(2.6 \times 10^{-3} \mathrm{kcal} / \mathrm{m}^{2}\right.$-sec${ }^{\circ} \mathrm{K}$ ) was then used to determine the wall temperature giving best fit to experimental results. The wall temperatures so determined were somewhat higher than ambient, as shown in Table 5, but not greatly so. In modeling of the deactivation transients, an average of the $T_{w}$ values obtained from the two inert sections was employed over the whole length of the reactor.

\section{Computation of reactor dynamics}

The system of eqns (4)-(9) was solved by a Crank-Nicholson method employing non-equidistant space steps and parabolic approximation of spatial difference quotients. Details of the procedure, which is generally applicable to diffusion models, will be reported elsewhere [23].

In Fig. 8 are shown results of the model calculations compared with experimental data on temperature profiles

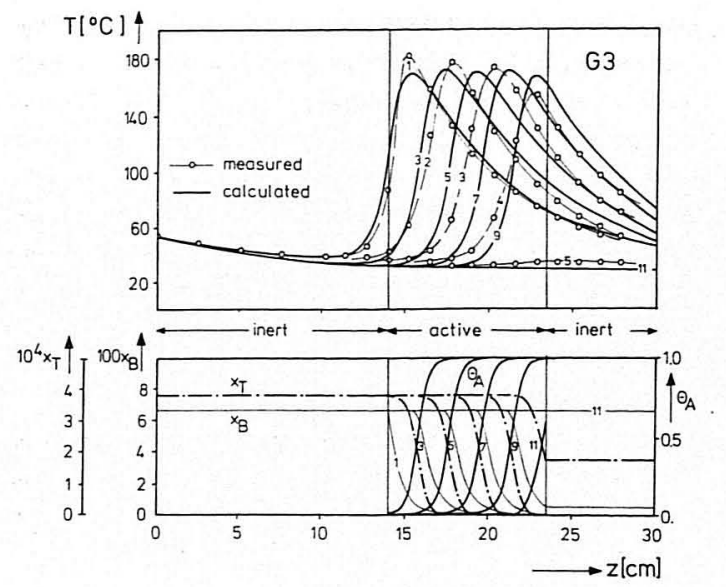

Fig. 8. Comparison of computed and experimental reactor dynamics for Run G3. Time marks: 1 -steady state, $t=0$; $2-t=30 \mathrm{~min} ; 3-t=60 \mathrm{~min} ; 4-t=90 \mathrm{~min} ; 5-t=120 \mathrm{~min} ; 6-$ $t=150 \mathrm{~min} ; 7-t=180 \mathrm{~min} ; 8-t=210 \mathrm{~min} ; 9-t=240 \mathrm{~min} ; 10-$ $t=270 \mathrm{~min} ; 11-t=300 \mathrm{~min}$.

from Run G3. The match to the initial steady-state profile is good, but that is the high point of the calculation. Clearly the calculated poisoning wave and corresponding hot spot location move through the bed much more slowly than was experimentally observed. For the example shown in Fig. 8 the zone of main reaction was at the end of the bed after $1.5 \mathrm{hr}$, while the corresponding calculation indicated $4 \mathrm{hr}$ for this to occur.

These results are typical of the fit obtained with this model to all runs; calculated profiles pass through the bed more slowly than those measured experimentally, typically with a velocity of about 0.4 of the experimental value. There are two possible explanations for this:

(1) The calculation was found to be sensitive to the value of $M_{T}$, the total adsorption capacity for thiophene. If $M_{T}$ is set at 0.4 of the experimentally determined value, the calculation gives a good correlation between theory and experiment for all the poisoning runs. However, while we can envision several reasons why the adsorption capacity experiment might have resulted in too small a value for $M_{T}$ (bypassing, thermal desorption effects, reaction of thiophene), it is difficult to see how that experiment could overestimate $M_{T}$. The magnitude of experimental error in thiophene concentration measurement with the isatin-sulfuric acid method is much below that required to explain a two-fold discrepancy.

(2) The kinetic model for catalyst poisoning, eqn (12), may be inadequate and, in fact, there is some chemical evidence for this possibility. Lyubarskii et al.[22] and Berg et al. [24] have reported for thiophene on nickel, and Maxted [25] for thiophene on a number of transition metals, that their hydrogenation activity is not linearly

Table 5. Reactor wall temperatures

\begin{tabular}{lcccccc}
\hline Run & G1 & G2 & G3 & G4 & G5 & G7 \\
\hline Ambient Temperature, ${ }^{\circ} \mathrm{C}$ & 19.0 & 23.0 & 22.0 & 23.0 & 23.0 & 22.0 \\
$\mathrm{~T}_{\mathrm{w}}$, Fore Section, ${ }^{\circ} \mathrm{C}$ & 32.0 & 33.0 & 35.0 & 33.0 & 33.0 & 32.0 \\
$\mathrm{~T}_{\mathrm{w}}$, Aft Section, ${ }^{\circ} \mathrm{C}$ & 27.5 & 25.0 & 23.0 & 25.0 & 25.0 & 23.0 \\
$\overline{\mathrm{T}}_{\mathrm{w}},{ }^{\circ} \mathrm{C}$ & 29.7 & 29.0 & 29.0 & 29.0 & 29.0 & 27.5 \\
\hline
\end{tabular}


related to the amount of poison on the surface. At lower loadings there is a large decrease in activity for small changes in loading, but at high values of loading the activity becomes independent of the amount of poison on the surface. In this case the adsorption capacity, $M_{T}$, as measured includes sites both active and inactive (or nearly so) for the hydrogenation reaction. The poisoning kinetics may then be treated to a much better approximation as shown below.

\section{A two site model for thiophene chemisorption}

If we consider the sites active for thiophene chemisorption to be the sum of those also active for hydrogenation and those active for chemisorption alone, the following balance equations may be written. For active sites:

$$
\frac{\mathrm{d} \theta_{A}}{\mathrm{~d} t}=r_{d}=-k_{d}^{0} P x_{T} \theta_{A} \mathrm{e}^{-E_{d} / R T}
$$

which is identical to eqns (2), (7) but where $\theta_{A}$ is defined as the ratio of hydrogenation active sites to the initial number of those sites. Since the kinetic parameters $k_{d}{ }^{0}$ and $E_{d}$ were measured experimentally by direct observation of the deactivation of the catalyst, they have the values given in Table 3 . Now, for sites inactive in hydrogenation:

$$
\frac{\mathrm{d} \theta_{I}}{\mathrm{~d} t}=-k_{d I}^{0} P x_{T} \theta_{I} \mathrm{e}^{-E_{d l} / R T}
$$

where $\theta_{I}$ is the fractional occupancy of sites active only for thiophene chemisorption. If the activation energies $E_{d}$ and $E_{d I}$ are about equal and the rate constants differ in magnidude such that $k_{d I}^{0}=f k_{d}{ }^{0}(0<f<1$, for preferential adsorption on hydrogenation active sites), the following relationship between $\theta_{A}$ and $\theta_{I}$ is established:

$$
\theta_{I}=\theta_{A}{ }^{f}
$$

the total rate of chemisorption of thiophene in this case is:

$$
-r_{T}=P x_{T} M_{T} k_{d}^{0} \mathrm{e}^{-E_{d} / R T}\left\{\gamma \theta_{A}+f(1-\gamma) \theta_{A}{ }^{f}\right\}
$$

where $\gamma$ is the ratio of hydrogenation active sites to the total number obtained from measurement of $M_{T}$. If the constraint on $E_{d} \approx E_{d I}$ is not satisfied, then eqns (12) and (13) must be used together to obtain $r_{T}$. In the present instance, these activation energies appear small (if not equal) so the relationship of eqn (14) is reasonable. Thus, the only change required to use the two site model in the computation is the substitution of eqn (15) for eqn (7).

\section{Discussion of results}

Using either the original model, with an $M_{T}$ of 0.4 the experimental value, or the two site model with the single set of parameters $f=0.015$ and $\gamma=0.35$, we have found it possible to obtain reasonable fits, essentially the same for both models, to all the experimental runs. Representative computed results are shown in Figs. 9-12 for Runs G3 to $\mathrm{G} 7$, both for the theoretical-experimental match on temperature profiles and for the computed values of $\theta_{A}, x_{B}$

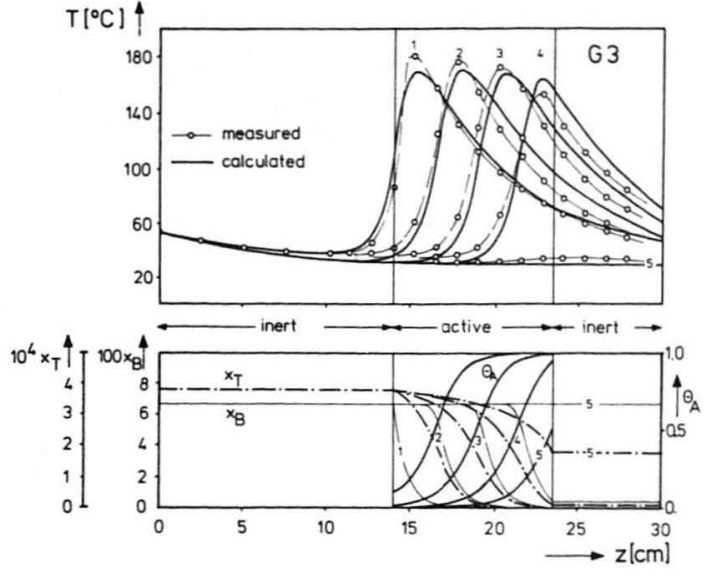

Fig. 9. Comparison of experimental temperature profile transients and calculated results from two-site deactivation model, Run G3. $1-t=0 ; 2-t=30 \mathrm{~min} ; 3-t=60 \mathrm{~min} ; 4-t=90 \mathrm{~min} ; 5-t=$ $120 \mathrm{~min}$.

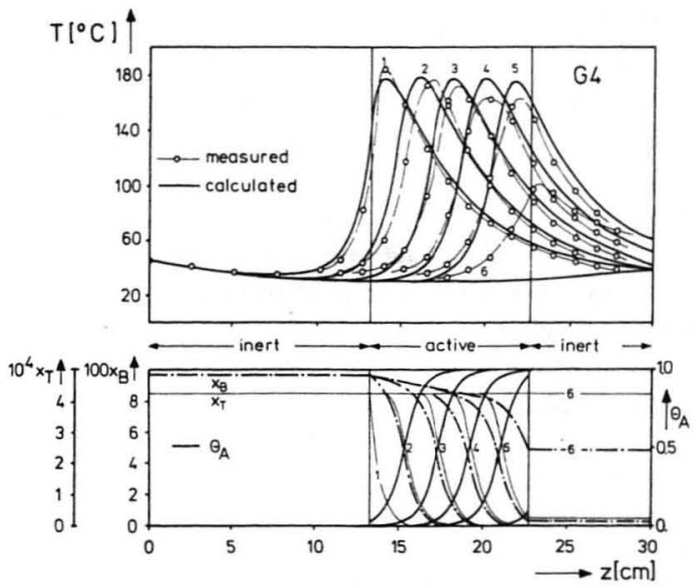

Fig. 10. Comparison of experimental temperature profile transitnts and calculated results from two-site deactivation model, Run G4. $1-t=0 ; 2-t=30 \mathrm{~min} ; 3-t=60 \mathrm{~min} ; 4-t=90 \mathrm{~min} ; 5-t=$ $120 \mathrm{~min} ; 6-t=150 \mathrm{~min}$.

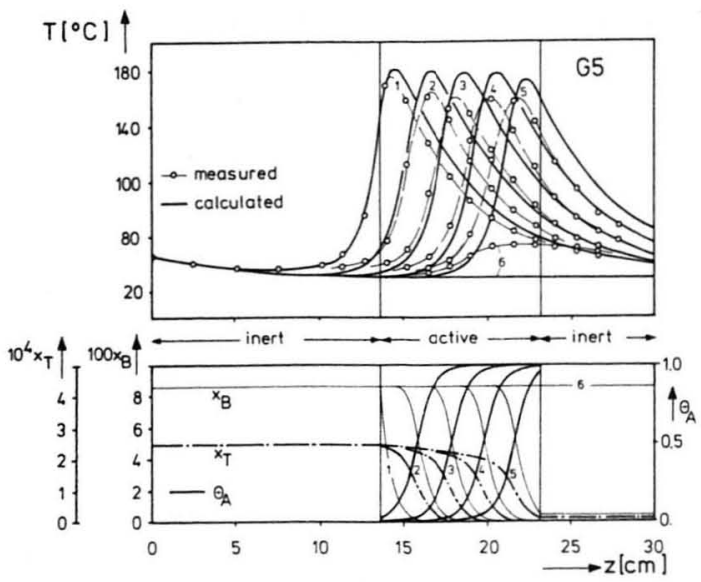

Fig. 11. Comparison of experimental temperature profile transients and calculated results from two-site deactivation model, Run G5. $1-t=0 ; 2-t=60 \mathrm{~min} ; 3-t=120 \mathrm{~min} ; 4-t=180 \mathrm{~min}$; $5-t=240 \mathrm{~min} ; 6-t=300 \mathrm{~min}$. 


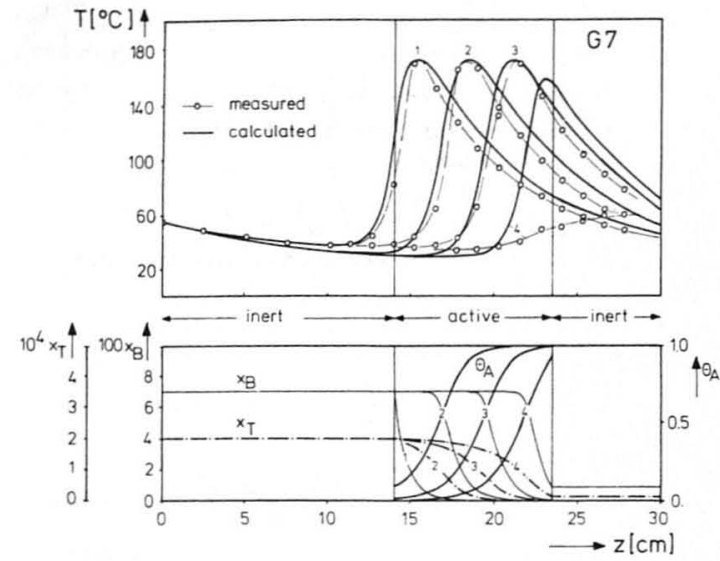

Fig. 12. Comparison of experimental temperature profile transients and calculated results from two-site deactivation model, Run G7. $1-t=0 ; 2-t=60 \mathrm{~min} ; 3-t=120 \mathrm{~min} ; 4-t=180 \mathrm{~min}$.

and $x_{T}$ through the reactor. The near-match between $\gamma=0.35$ in the two site model and the 0.4 factor on $M_{T}$ required to force the single site model fit supports the plausibility of a two site chemisorption process in which $35-40 \%$ of total sites are active for the hydrogenation reaction. It should be noticed that while the activity and concentration gradients are rather sharp in most instances, corresponding to a moving active zone of about one-fifth the total catalyst bed, the thiophene and activity gradients in G3 and G7 extend through a large fraction of the bed length after initial operation. Thus, poison and activity "waves" may not be as sharp as the temperature gradients might lead one to expect.

In calculations with both models it was found that axial mass dispersion had only very small effects on the computed temperature profiles. An effective diffusivity for average experimental conditions, computed from a correlation such as that of Evans and Kenney[26], is $0.35 \times 10^{-4} \mathrm{~m}^{2} / \mathrm{sec}$, almost the same as the molecular diffusivity reported in Table 4 . If desired, then, axial mass dispersion could be included in the models with an axial diffusivity of the same magnitude as the molecular diffusivity.

The calculated exit concentration of benzene is compared with experimental results in Fig. 13 for Run G5, which has about the porrest agreement between experiment and calculation of the series. The time of initial breakthrough of benzene from the reactor is very well predicted, although the calculation underestimates by about $10 \%$ the time required for complete deactivation of the bed. Also shown in Fig. 13 is the calculated thiophene concentration at the exit. This is qualitatively similar to the experimental results shown in Fig. 7 but a detailed comparison is not possible since no thiophene concentrations were measured in these runs.

The values of the parameters $\gamma$ and $f$ obtained in the fit with the two site model are reasonable in terms of their physical significance in the model. The $f$ value indicates that thiophene chemisorption on the sites inactive for hydrogenation is slow compared to that on active sites, while the $\gamma$ value indicates that there are somewhat fewer hydrogenation-active sites than inactive sites and as stated above this is in quantitative agreement with one site results. However, we cannot claim that this is a complete representation of the state of the catalyst surface without more detailed results on the intrinsic kinetics of thiophene poisoning of supported nickel.

\section{CONCLUSIONS}

While the present research has demonstrated agreement between reactor dynamics simulation and experiment, we have not yet attained the ultimate objective of complete, a priori prediction of dynamics due to poisoning using model parameters derived entirely from independent experimentation. A recurring theme is that poisoning kinetics in a reaction system such as this seem to be much more complex than the literature has generally given them credit for[1]. The entire question of linear poisoning models and of kinetic separability[15] between reaction processes and deactivation processes should be examined in detail, particularly for Langmuir-Hinshelwood rate correlations.

Acknowledgements - This research was supported by the National Science Foundation, GK-17200, by the Donors of the Petroleum Research Fund administered by the American Chemical Society, PRF-5087, and by the Deutsche Forschungsgemeinschaft. H-S. W. acknowledges partial fellowship support from the National Science Council, Republic of China.

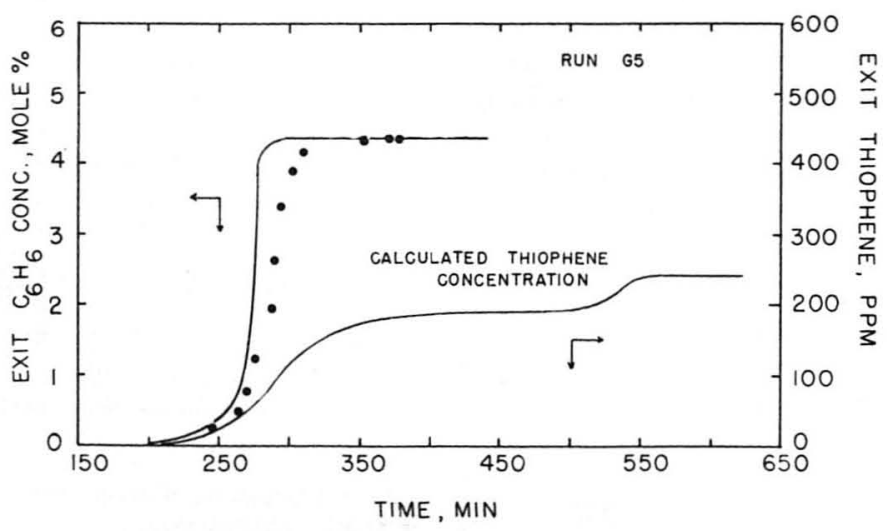

Fig. 13. Comparison of computed and measured exit benzene concentrations, Run G5. ๑, Experimental; ——, Calculated. 


\section{NOTATION}

$C_{B}, C_{T}$ concentrations of benzene and thiophene, respectively $\left(\mathrm{kmole} / \mathrm{m}^{3}\right)$

$C_{p g}$ heat capacity of the gas $\left(\mathrm{kcal} / \mathrm{kg}-{ }^{\circ} \mathrm{K}\right)$

$D_{B}, D_{T}$ molecular diffusivity of benzene and thiophene, respectively $\left(\mathrm{m}^{2} / \mathrm{sec}\right)$

$D_{p}$ particle diameter (m)

$E, E_{d}$ activation energies for hydrogenation and thiophene poisoning $(\mathrm{kcal} / \mathrm{kmole})$

$E_{d}, E_{d l}$ activation energies for two site poisoning model $(\mathrm{kcal} / \mathrm{kmole})$

$f$ ratio of pre-exponential factors for poisoning of inert of active sites

$\Delta H_{R}$ heat of benzene hydrogenation reaction ( $\mathrm{kcal} / \mathrm{kmole})$

$k_{i}^{0}, k^{0}$ rate constant for hydrogenation reaction on fresh and poisoned catalysts (kmole/kg-sectorr)

$k_{d}^{0}$ pre-exponential factor for thiophene poisoning, one site model (torr-sec) ${ }^{-1}$

$k_{d A}^{0}, k_{d I}^{0}$ pre-exponential factors for two site poisoning model, $(\mathrm{kg} / \mathrm{ksites}$-torr $)$

$K^{0}$ adsorption constant for benzene (torr) ${ }^{-1}$

$l$ reactor length $(\mathrm{m})$

$M_{T}$ catalyst adsorption capacity for thiophene $(\mathrm{kmole} / \mathrm{kg})$

$P$ total pressure (torr)

$p_{1.2}$ constant appearing in eqn (11)

$Q$ heat of adsorption parameter (kcal/ $/ \mathrm{kmole})$

$r_{B}, r_{d}$ rates of hydrogenation (kmole/kg-sec) and poisoning $\left(\theta_{A} / \mathrm{sec}\right)$

$r_{T}$ rate of total thiophene chemisorption (kmole/kg-sec)

$R$ gas constant $\left(\mathrm{kcal} / \mathrm{kmole}-{ }^{\circ} \mathrm{K}\right)$

$R_{r}$ reactor radius (m)

$t$ time (sec)

$T$ temperature $\left({ }^{\circ} \mathrm{K}\right.$ or $\left.{ }^{\circ} \mathrm{C}\right)$

$T_{w}, \bar{T}_{w}$ wall temperature and average wall temperature $\left({ }^{\circ} \mathrm{K}\right.$ or $\left.{ }^{\circ} \mathrm{C}\right)$

$T_{0}, T_{L}$ inlet and outlet temperatures from inert reactor sections $\left({ }^{\circ} \mathrm{K}\right.$ or $\left.{ }^{\circ} \mathrm{C}\right)$

$v$ interstitial velocity, $\mathrm{m} / \mathrm{sec}$

$\bar{v}$ constant appearing in eqn (11)

$x_{B}, x_{H}, x_{T}$ mole fractions of benzene, hydrogen and thiophene

$Y_{i}$ quantity defined in eqn (8)

$z$ length variable $(\mathrm{m})$

\section{Greek symbols}

$\alpha$ wall heat transfer coefficient $\left(\mathrm{kcal} / \mathrm{m}^{2}-{ }^{\circ} \mathrm{K}\right)$

$\alpha_{1}$ constant appearing in eqn (11) $\alpha_{w} \quad$ constant appearing in eqn (11)

$\gamma$ ratio of hydrogenation-active sites to total sites measured by $M_{T}$

$\epsilon$ bed void fraction

$\lambda_{\text {eff }}$ bed effective thermal conductivity $(\mathrm{kcal} / \mathrm{m}$ sec- ${ }^{\circ} \mathrm{K}$ )

$\theta_{A}, \theta_{I}$ fractional occupancy of hydrogenation-active and -inactive sites by thiophene

$\rho_{\mathrm{c}}, \rho_{\mathrm{g}}$ catalyst and gas densities $\left(\mathrm{kg} / \mathrm{m}^{3}\right)$

$\rho C_{p}$ average volumetric heat capacity $\left(\mathrm{kcal} / \mathrm{m}^{3}-{ }^{\circ} \mathrm{K}\right)$

\section{REFERENCES}

[1] Butt J. B., Adv. Chem. 1972109259.

[2] Eberly P. E., Jr., Kimberlin C. N., Miller W. H. and Drushel H. V., Ind. Engng Chem. Proc. Design Devel. 19665193.

[3] Menon P. G. and Sreeramamurthy R., J. Catal. 1967895.

[4] Menon P. G., Sreeramamurthy R. and Murti P. S., Chem. Engng Sci. 197227647.

[5] Kungita E., Saga K. and Otake T., J. chem. Engng Japan 1969275.

[6] Lambrecht G. C., Nussy C. and Froment G. F., 5th European Symp. on Chem. Reaction Engng B2-19, Elsevier, Amsterdam, 1972.

[7] Froment G. F. and Bischoff K. B., Chem. Engng. Sci. 196116 189.

[8] Pexidr V., Cerny J. and Pasek J., 4th European Symp. on Chem. Reaction Engng p. 239. Pergamon Press, Oxford, 1970.

[9] Richardson J. T., J. Catal. 197121130.

[10] Bohart G. and Adams E., J. Am. Chem. Soc. 192042523

[11] Irving J. P. and Butt J. B., Chem. Engng Sci. 1967221857.

[12] Kehoe J. P. G., Ph.D. Dissertation, Yale University. New Haven, Conn., 1971.

[13] Weng H. S., Ph.D. Dissertation, Northwestern University, Evanston, Ill., 1974. Available from University Microfilms.

[14] Kehoe J. P. G. and Butt J. B., J. appl. Chem. Biotechnol. 1972 2322.

[15] Szepe S. and Levenspiel O., 4th European Symp. on Chem. Reaction Engng p. 265, Pergamon Press, Oxford, 1970.

[16] Froment G. F., Ind. Engng Chem. 19675918.

[17] Finlayson B. A., The Method of Weighted Residuals and Variational Principles, p. 131. Acedmic Press, New York, 1972.

[18] Butt J. B. and Weekman V. W., Jr., CEP Symp. Series 143. 1974; 7027 Mears, D. E., Ind. Engng Chem. Proc. Des. Develop. 197110541.

[19] Littman H., Barile R. G. and Pulsifer A. H., Ind. Engng Chem. Proc. Des. Develop. 197110541.

[20] Yagi, S. and Kuni D., A. I. Ch. E. Jl. 19573373.

[21] Krischer O. and Kroll K., Die wissenschaftlichen Grundlagen der Trocknungstechnik, p. 176, Springer-Verlag, Berlin, 1963.

[22] Lyubarskii G. D., Andeeva L. B. and Kul'kova N. V., Kin. i Kat. 19623123.

[23] Eigenberger G. and Butt J. B., A Crank-Nicholson Method with Non-equidstant Space Steps, to be published.

[24] Berg G. A., Sokolova, V. I. and Masagutov R. M., Tr. Bashkir. Nauk. Issled, Inst. Pererab. Nefti. 19688115.

[25] Maxted E. B., Adv. Catalysis 19513129

[26] Evans E. V. and Kenney C. N., Trans. Instn. Chem. Engrs. $196644 \mathrm{~T} 189$. 